\title{
OS MATIZES DO VINHO E SUAS DEFINIÇÕES: UM ESTUDO EM SEMÂNTICA COGNITIVA ${ }^{1}$
}

\author{
Cristine Henderson Severo*
}

\begin{abstract}
RESUMO: A Análise Sensorial Enológica apresenta um conjunto de termos para expressar as tonalidades do vinho, como branco, tinto, vermelho-rubi, etc, que são de difícil definição, pois ainda podem fornecer indícios sobre a idade do vinho. Deste modo, este trabalho procura evidenciar as propriedades conceituais de 18 termos que designam tonalidades do vinho, a fim de facilitar a construção de definições. O referencial teórico adotado localiza-se nos estudos da semântica cognitiva de Kleiber (1990) e de Dubois (1997, 2000 e 2005). Os resultados indicam que a descrição das propriedades conceituais é necessária na medida em que permite verificar as informações que precisam constar em uma definição.
\end{abstract}

PALAVRAS-CHAVE: Semântica Cognitiva - Léxico Sensorial Enológico - Terminologia

ABSTRACT: The Sensorial Analysis of Wine presents a set of terms to express the tonalities of wine, as white, red, red-ruby, etc, which are difficult to define, because they still can supply indications on the age of the wine. Considering this, this paper aims to evidence the conceptual properties of 18 terms that assign wine tonalities, in order to facilitate the construction of definitions. The adopted theoretical referential is situated in the studies of the cognitive semantics by Kleiber (1990) and Dubois (1997, 2000 and 2005). The results indicate that the description of the conceptual properties is necessary since it permits verifying the information that has to consist in a definition.

KEYWORDS: Cognitive Semantics - Sensorial Analysis of Wine Lexicon - Terminology

\section{INTRODUÇÃO}

$\mathrm{Na}$ linguagem de especialidade denominada Análise Sensorial Enológica (doravante ASE), os termos para expressar as tonalidades manifestadas pelo vinho, como branco, vermelho-rubi, amarelo nítido, etc, podem fornecer indícios sobre a idade do vinho. Por exemplo, um termo como vermelho-rubi indica que o vinho ainda é jovem. Entretanto, como se pode observar em glossários e dicionários da área, existem dificuldades em propor definições a esses termos, devido à falta de uma descrição prévia das propriedades dos conceitos de cada termo.

A partir dessas considerações, este trabalho procura evidenciar as propriedades conceituais daqueles termos, contribuindo para a elaboração de suas definições. Para tanto, optou-se por uma abordagem cognitivista da linguagem: a semântica dos protótipos, versão standard, apresentada por Kleiber (1990), e a análise de Danièle Dubois $(1997,2000,2005)$.

\footnotetext{
${ }^{1}$ Uma versão deste trabalho foi apresentada como trabalho de conclusão de curso sob orientação da Profa. Dra. Sabrina Pereira de Abreu.

Aluna do Programa de Pós-graduação em Letras do Instituto de Letras (UFRGS). E-mail: cristinesevero@ibest.com.br
} 


\section{O LÉXICO DA ANÁLISE SENSORIAL ENOLÓGICA (ASE)}

Toda a análise deve dispor de critérios objetivos para se chegar a resultados confiáveis. No entanto, o julgamento sobre a qualidade de um vinho depende das impressões causadas em um sujeito no momento da degustação. Ou seja, os critérios para o exame da bebida são construídos a partir das percepções obtidas pelos sentidos da visão, do olfato e do paladar.

Durante as três fases da análise (visual, olfativa e gusto-olfativa, e gustativa), o degustador necessita nomear a sensação percebida. Não havendo um nome que a denote, a comparação torna-se um processo recorrente. Por exemplo, na análise visual, se o vinho tinto manifesta uma tonalidade $\mathrm{x}$, essa tonalidade pode não ser contemplada com a criação de uma nova palavra. Mas se essa tonalidade guardar semelhanças com a coloração atribuída à pedra rubi, a tonalidade será designada como vermelho-rubi.

Como afirmam Abreu \& Lara (2003, p.57), ao analisarem o léxico olfativo da ASE, a linguagem da análise sensorial é construída a partir da comparação do vinho com outras entidades da natureza. Desta forma, uma semântica lexical fundada na tríade objeto-termo-conceito não é suficiente para uma descrição de todas as propriedades a que os termos daquele léxico se referem: "No tocante ao léxico olfativo, o referente (o objeto ou coisa) não é uma entidade discreta, mas um conjunto de propriedades dispostas num espectro contínuo" (ibid, p. 37). O mesmo se pode dizer a respeito dos termos que designam tonalidades. Vermelho-rubi consiste também em um "conjunto de propriedades dispostas num espectro contínuo", pois representa uma determinada tonalidade diferenciada em relação às outras.

Considerando as especificidades desses termos, este trabalho tratará de evidenciar as suas propriedades conceituais, para a construção de definições adequadas. Rey (1979, p. 49) afirma que a definição procura explicitar os traços pertinentes da conceituação e somente esses traços. Já à descrição, cabem não apenas os traços pertinentes, mas os traços característicos. Dito de outra forma, a descrição abrange tanto as propriedades de um termo que o fazem distinguir de outro termo (traços característicos), como as propriedades que fazem desse termo reconhecível como elemento de uma determinada classe (traços pertinentes). Enquanto a definição trata apenas das propriedades que fazem com que um objeto como uma cadeira, seja identificado como tal, a descrição fica a cargo de todas as propriedades reconhecíveis do mesmo móvel. Se na definição somente os traços pertinentes precisam constar, por que há dificuldades em se propor definições adequadas?

Sabe-se que um traço [+ móvel], por exemplo, é um atributo necessário para a definição do objeto cadeira. Mas um traço como [+descanso para mão] não é necessário à definição, já que podem existir cadeiras que não apresentam esse traço e continuam sendo chamadas de cadeiras. Porém, considerando os termos que designam tonalidades, não há clareza sobre o que é apenas característico em um objeto e o que é pertinente no mesmo objeto. As dificuldades em propor definições para os termos, independentemente da área temática a que pertencem, residem na falta de uma descrição das propriedades dos conceitos de cada termo e na inadequação de padrões definitórios que não abrangem as especificidades de cada termo.

Como apontam Krieger \& Finatto (2004, p. 93), a construção de uma definição clássica parece requerer apenas a tarefa de seguir a estrutura gênero próximo + 
diferença específica. A primeira parte da estrutura está associada à identificação de uma classe. Já a segunda parte diferencia o elemento entre todos os outros pertencentes à mesma categoria. Entretanto, não é o que se constata ao se propor uma definição ao termo vermelho-rubi. Se, por um lado, não parece haver dúvidas de que o gênero próximo seja o de ser uma tonalidade do vinho tinto, não é claro qual propriedade consiste na diferença específica dessa entidade.

ENTRADA: vermelho-rubi

DEFINIÇÃO 1: tonalidade do vinho tinto ("gênero próximo") + que se assemelha à cor do rubi ("diferença específica")

DEFINIÇÃO 2: tonalidade do vinho tinto ("gênero próximo") + que indica que o vinho está em um estágio menos avançado de envelhecimento ("diferença específica")

DEFINIÇÃO 3: tonalidade do vinho tinto ("gênero próximo") + que se assemelha à cor do rubi ("diferença específica") + que indica que o vinho está em um estágio menos avançado de envelhecimento ("diferença específica")

Num primeiro momento, pode-se dizer que a última definição mostra as propriedades principais do conceito do termo vermelho-rubi. Ainda assim, pode-se questionar o estatuto dessas propriedades e como estão organizadas no conceito, o que revela que é preciso apontar as propriedades de cada conceito, antes de se propor definições. Mas como podemos descrever essas propriedades? Dois modelos de descrição são apresentados nas seções seguintes.

\section{A SEMÂNTICA DOS PROTÓTIPOS: PRINCÍPIOS DA VERSÃO STANDARD}

Para a semântica cognitiva, a significação é estudada "como uma parte própria da cognição humana (...) em relação intrínseca com as capacidades cognoscitivas gerais" (SILVA, 1999, p.14), como a categorização e a conceituação. Entende-se que as categorias são formadas pelos indivíduos a partir de sua experiência no mundo. Por exemplo, é mais fácil identificar o item PARDAL como pertencente à categoria AVE do que o item PINGÜIM. De acordo com a nossa experiência de mundo, PARDAL é um item mais representativo da categoria AVE. Tanto PARDAL como PINGÜIM possuem as propriedades que possibilitam classificá-los como categorias de AVE, mas PARDAL é identificado mais rapidamente. Assim, para se fazer uma classificação, não é necessário saber se um item possui as propriedades comuns aos outros itens de uma categoria, mas saber se esse item se assemelha aos casos mais exemplares. É a partir dessas considerações que se desenvolve a teoria dos protótipos como um modelo de representação de conceitos no quadro da semântica cognitiva.

Segundo essa teoria, "as categorias estão estruturadas segundo uma escala de prototipicidade que vai dos representantes idôneos (...) aos exemplares menos apropriados" (KLEIBER, 1990, p.176). O representante mais idôneo recebe o nome de protótipo: exemplar que resume as propriedades prioritárias da categoria, sem ser um exemplar particular, mas uma construção mental, fruto de operações cognitivas (ibid., p. 61).

A noção de protótipo é fundamental para a descrição da representação conceitual de um item na medida em que permite situar quais propriedades daquele conceito são mais prototípicas e quais são menos prototípicas. Isto é, se sabemos quais itens lexicais 
são mais representativos de uma categoria, há condições de verificar como se compõe o conceito de cada item lexical. Como afirma Oliveira, "os conceitos se estruturam por protótipos" (2001, p. 40).

Assim sendo, nem todos os itens de uma categoria possuem o mesmo estatuto, isto é, os diferentes nomes possíveis para um mesmo objeto particular não são totalmente equivalentes, já que pertencem a níveis de categorização diferenciados:

1) nível superordenado: nível onde estão as categorias mais amplas, que não possuem uma informação geral definida, nem é possível identificar com facilidade o tipo de interação que se estabelece com o objeto designado pela categoria. Um exemplo é a categoria ANIMAL;

2) nível básico: em relação ao nível anterior, as categorias em nível básico apresentam informação menos geral e já é possível verificar o tipo de interação que se estabelece com o objeto. A categoria básica ocupa um estatuto privilegiado em relação às demais, pois é identificada mais rapidamente pelos indivíduos. Seguindo o exemplo de ANIMAL, a categoria em nível básico é CACHORRO. Outra característica importante desse nível é que "os lexemas de base tendem a ser os lexemas primários mais curtos" e parecem ser "os primeiros que entram no léxico de uma língua" (KLEIBER, 1990, p. 83);

3) nível subordinado: nível das categorias mais específicas e que ocupam posições periféricas na constituição do conceito. Pode-se apontar uma forma geral e o tipo de interação a ser estabelecida, mas não são rapidamente identificáveis, por isso, não possuem estatuto privilegiado. Considerando o exemplo de ANIMAL e CACHORRO, a categoria DACHSHUND ocupa esse nível mais periférico.

Deste modo, é possível estabelecer que os conceitos dos termos que designam tonalidades na ASE estão construídos em planos de descrição conceitual: das propriedades mais prototípicas até as propriedades menos prototípicas. Kleiber assinala que "não se trata de levantar a equivalência sentido de um termo = protótipo de uma categoria", mas sim de "dar conta das manifestações cognitivas do protótipo, especialmente de suas manifestações lingüísticas" (1990, p. 178, grifos do autor). Mas como poderiam ser identificadas as manifestações lingüísticas da categoria vermelho, por exemplo? Torna-se necessário analisar como aqueles termos são constituídos.

\section{Os termos da ASE: cores básicas e valores focais}

Sobre as categorias de cores na LC, Taylor (apud LARA, 2002) verificou que existem pontos de referência centrais entre os diferentes matizes: "As categorias de cores têm um centro e uma periferia. Isto significa que, ao contrário da visão estruturalista, membros de uma categoria não têm o mesmo status" (LARA, 2002). Esses pontos centrais são chamados de cores focais. Vermelho-rubi, no âmbito da língua comum, não é uma cor focal, mas apenas um tom da cor focal vermelho. Pode-se dizer, então, que a descrição de um conceito de uma tonalidade tem como início a determinação da cor focal à qual aquela tonalidade está ligada.

No entanto, Lara (2002) conclui que o estabelecimento de cores focais em LEs se dá de uma maneira diferente da LC:

Ao contrário do que se passa na língua comum, em que vermelho-granada e vermelho-tijolo são apenas tons de uma categoria, passíveis de serem intercambiados, estes termos nunca serão confundidos pelos especialistas em 
enologia, pois constituem termos focais, muito específicos, que caracterizam o vinho precisamente, opondo-os às demais (...) categorias de vermelho (LARA, 2002, grifos do autor).

Assim, no âmbito da LC, o conceito de vermelho-rubi é descrito a partir da cor focal com a qual aquele conceito está ligado. Dito de outra forma, a cor focal na LC (vermelho) é parte do conceito de vermelho-rubi. Já na ASE, vermelho-rubi é a própria cor focal. Então, o item é parte do conceito das categorias com as quais mantém limite. Assim, na ASE, saber a delimitação de uma categoria que expressa uma tonalidade é saber parte do conceito daquela categoria. Ao propor a delimitação da categoria como parte de seu conceito, identifica-se a sua localização em relação ao espectro de matizes ao qual a categoria faz parte.

Além da delimitação da categoria, outro detalhe existente é o fato de vermelho e rubi atuarem de alguma forma na constituição do conceito de vermelho-rubi, já que não é possível afirmar que o termo tenha sido criado arbitrariamente. Por esse motivo, se as partes não podem ser consideradas cores focais separadamente, por outro lado, podem ser entendidas como valores que constituem o conceito de uma tonalidade: (1) a cor básica, que pode aparecer sozinha; e (2) o valor focal, ou seja, o elemento que indica as informações do conceito da cor básica que serão relevantes na constituição do conceito final, como rubi em vermelho-rubi, ou como nítido em amarelo nítido.

Ao se defender que as informações do conceito de cada categoria estão organizadas prototipicamente, desenha-se uma estrutura para a descrição dos conceitos. Porém, ainda ignora-se um ponto crucial na ASE: o fato desta se realizar através das impressões suscitadas em um determinado sujeito, o degustador, que está inserido em uma determinada cultura.

\section{AS CONSIDERAÇÕES DE DUBOIS SOBRE O LÉXICO VISUAL}

Por mais que a ASE seja realizada através de métodos dedutivos, o ato de atribuir uma determinada tonalidade consiste sempre em uma atitude subjetiva de um degustador. A semântica dos protótipos não parece dar conta desse aspecto. Mas será que esse aspecto é apenas outra propriedade do conceito? Danièle Dubois (2005) mostra que a categorização das cores no léxico comum é influenciada pelas atividades humanas desempenhadas na sociedade. Se esse aspecto subjetivo é encontrado nos conceitos, então, não se trata de uma propriedade conceitual, mas de um princípio que orienta a categorização e, conseqüentemente, a conceituação.

Em outro artigo, Dubois (2005) conclui que as culturas não abstraem da mesma maneira o conceito de uma cor, pois entende que a percepção "não é um processo bottom-up, mas uma habilidade complexa dirigida por práticas culturais" (id., 1997, p. 188, grifos da autora). Se o conceito de cor não é abstraído da mesma maneira, então, a redução da cor a um conhecimento fundado em uma teoria física da luz "ignora sua semântica" (id., 1997, p. 188), baseada na prática e no conhecimento.

Dubois $(2005$, p. 3) afirma que a cor não é um primitivo perceptual, mas um "conceito, uma abstração, um conhecimento construído". Assumir a concepção de que toda a cor é um conceito implica dizer que a lexicalização dessa cor deriva de processos cognitivos. Isto é, a lexicalização da cor deriva de processos individuais (baseados diretamente na experiência visual) e coletivos (originados na construção de conceitos pertencentes a uma determinada cultura). 
As considerações de Dubois parecem ser adequadas à análise dos termos que designam tonalidades na ASE. Entre os processos individuais que podem ter permitido a atribuição de vermelho-rubi a uma tonalidade manifestada pelo vinho, pode-se dizer que está a metáfora, a comparação de um determinado matiz manifestado pelo vinho à coloração da pedra rubi. Já entre os processos coletivos, está a admissão da comparação feita acima pela comunidade especializada em enologia.

Tem-se assim que os efeitos que as impressões obtidas pelo sentido da visão causam no indivíduo são essenciais para a conceituação de um termo como vermelhorubi. Poitou \& Dubois (1999, p.2) concluem que, enquanto a cor tem sido colocada como uma dimensão objetiva do mundo, que está fora do sujeito, a nomeação de odores é comumente feita pela nomeação da fonte. Por exemplo, se um determinado produto possui o odor de lavanda, provavelmente esse odor será denominado apenas como "lavanda". Não há a criação de um novo nome para designar a sensação suscitada, bastando a indicação da fonte que permitiu que aquele odor fosse produzido. O estudo do léxico olfativo comprova assim que os princípios de categorização são orientados não apenas pelas atividades humanas baseadas em processos cognitivos individuais e coletivos, mas pelos efeitos causados no sujeito. Se o léxico olfativo possui estas características, é preciso reconsiderar se o léxico visual se refere realmente a uma dimensão puramente objetiva.

No caso do termo vermelho-rubi, se o léxico visual é puramente objetivo, por que entre todos os elementos da natureza foi a coloração da pedra rubi a escolhida e comparada a uma determinada tonalidade do vinho? Por que a especificação nítido foi atribuída à cor básica amarelo, e não outro tipo de especificação? As duas perguntas parecem que só podem ser respondidas ao se considerar que no processo que permitiu a lexicalização daquele termo, ou seja, no processo em que um determinado valor focal foi atribuído a uma cor básica, houve a intervenção de um sujeito. Assim, além das propriedades físicas inerentes às categorias, é preciso descrever a maneira como as categorias são percebidas. Tendo por base essas considerações, na próxima seção serão apresentados os procedimentos metodológicos adotados na pesquisa.

\section{PROCEDIMENTOS METODOLÓGICOS}

\section{Do Corpus}

O corpus foi recolhido a partir dos dados de Lara (2002). Foram consideradas unidades de análise os termos que apresentaram maior produtividade em sites destinados ao leitor que domina o léxico especializado da Enologia. As obras que serviram para a seleção dos dados foi Degustação de vinhos, de Vitor Manfroi e os sites ABE - Associação Brasileira de Enologia e Academia do Vinho. Assim, chegou-se a um corpus de 18 tonalidades:

Tabela 1 - Corpus total 


\begin{tabular}{|c|c|c|}
\hline $\begin{array}{ll}\text { 1. } & \text { Amarelo-âmbar } \\
\text { 2. } & \text { Amarelo-dourado } \\
\text { 3. } & \text { Amarelo-palha } \\
\text { 4. } & \text { Amarelo nítido } \\
\text { 5. } & \text { Branco com reflexos } \\
\text { 6. } & \text { Branco com reflexos } \\
& \text { alaranjados }\end{array}$ & 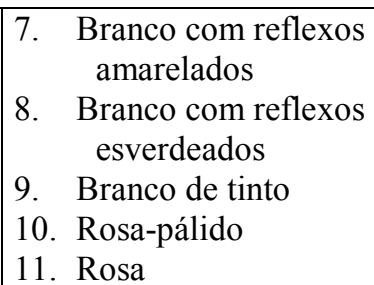 & $\begin{array}{l}\text { 12. Rosa-cereja } \\
\text { 13. Vermelho-rubi } \\
\text { 14. Vermelho tijolo } \\
\text { 15. (Vinho) branco } \\
\text { 16. (Vinho) rosado } \\
\text { 17. (Vinho) tinto } \\
\text { 18. Vermelho-violáceo }\end{array}$ \\
\hline
\end{tabular}

Abaixo, é apresentada uma escala das tonalidades, que, baseada nos estudos de Manfroi (2004, p.75) e Lara (2002), corresponde à idade que o vinho pode ter.

Tabela 2 - Escala dos vinhos relacionados à sua idade

\begin{tabular}{|c|c|c|c|c|c|c|c|c|c|c|c|c|c|}
\hline 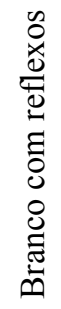 & 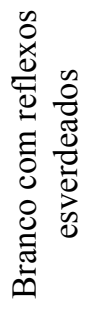 & 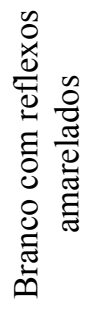 & 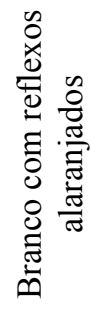 & 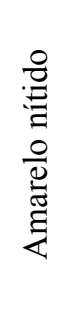 & 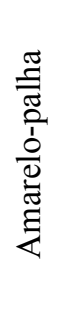 & 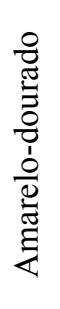 & 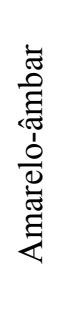 & 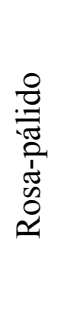 & $\begin{array}{l}\mathscr{D} \\
\stackrel{0}{0} \\
\stackrel{1}{1}\end{array}$ & 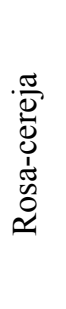 & 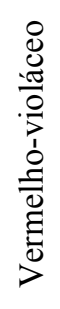 & 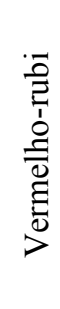 & 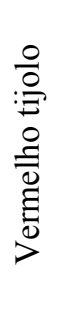 \\
\hline \multicolumn{8}{|c|}{ Branco } & \multicolumn{3}{|c|}{ Rosado } & \multicolumn{3}{|c|}{ Tinto } \\
\hline \multicolumn{2}{|c|}{+ jovem } & -jove & & \multicolumn{2}{|c|}{+ jovem } & \multicolumn{2}{|c|}{-jovem } & \multicolumn{3}{|c|}{ +jovem $\rightarrow$-jovem } & \multicolumn{3}{|c|}{+ jovem $\rightarrow$-jovem } \\
\hline
\end{tabular}

A pesquisa conta com 8 (oito) ocorrências que designam tonalidades do vinho branco; do vinho rosado, com 3 (três); e do vinho tinto, também com 3 (três) ocorrências. Apenas a categoria branco de tinto não se refere ao estágio de desenvolvimento, mas ao método de elaboração do vinho ${ }^{2}$. Feitas essas considerações sobre a seleção do corpus, é possível dividir os termos em duas classes em relação à maneira como são especificados:

(1) Termos que apresentam metaforização, em que os valores focais recuperam uma imagem externa ao léxico das cores: amarelo-âmbar, amarelo-dourado, amarelo-palha, branco de tinto, vermelho-rubi, vermelho-tijolo e rosa-cereja;

(2) Termos que apresentam especificação, em que, ao contrário da metaforização, não se recupera uma imagem externa que possa auxiliar na caracterização de uma determinada cor básica: amarelo nítido, branco com reflexos, branco com reflexos alaranjados, branco com reflexos amarelados, branco com reflexos esverdeados, rosa-pálido e vermelho-violáceo.

Esta divisão torna-se mais aparente quando, ao se tentar descrever o sentido de determinados itens lexicais, utilizam-se construções sintáticas análogas (que poderão ser usadas nas definições) aos termos. Para a primeira classe de termos, sendo metáforas, os seguintes padrões [do tipo $\mathrm{x}$ ] e [que se assemelha a $\mathrm{x}$ ] poderão ser utilizados:

\footnotetext{
${ }^{2}$ Um vinho branco de tinto é o vinho produzido a partir de uvas tintas vinificadas de bica aberta (conforme o site E-MERCATURA.NET).
} 
Tabela 3 - Construções sintáticas de termos que contêm metáforas

\begin{tabular}{|c|c|c|}
\hline Termos & [do tipo x] & [que se assemelha a x] \\
\hline amarelo-âmbar & (?) amarelo do tipo âmbar. & amarelo que se assemelha a âmbar \\
\hline amarelo-dourado & amarelo do tipo dourado. & amarelo que é dourado \\
\hline amarelo-palha & amarelo do tipo palha & amarelo que se assemelha a palha \\
\hline branco de tinto & (?) branco do tipo de tinto. & branco que se assemelha a tinto \\
\hline vermelho-rubi & vermelho do tipo rubi & vermelho que se assemelha a rubi \\
\hline vermelho-tijolo & vermelho do tipo tijolo & vermelho que se assemelha a tijolo \\
\hline Rosa-cereja & rosa do tipo cereja & rosa que se assemelha a cereja \\
\hline
\end{tabular}

Para os termos acima, o padrão [que se assemelha a $\mathrm{x}$ ] poderá ser utilizado nas definições. Para os termos que se enquadram no segundo tipo de especificação, são necessárias construções sintáticas diferentes. Pode-se usar uma construção demasiadamente geral, como [que é x]; já para os termos que possuem a preposição "com", as construções formadas a partir de [que tem x] e [que são x] parecem válidas. As construções que não parecem válidas, isto é, que não constituem construções sintáticas análogas aos termos, recebem um asterisco (*) no início do sintagma, como se demonstra na tabela abaixo:

Tabela 4 - Construção sintática de termos com especificação

\begin{tabular}{|c|c|c|}
\hline Termos & [que tem $x]$ & [que é $x]$ \\
\hline amarelo nítido & amarelo que tem nítido. & amarelo que é nítido \\
\hline branco com reflexos & branco que tem reflexos & *branco que é reflexos \\
\hline branco com reflexos alaranjados & $\begin{array}{c}\text { braço que tem reflexos } \\
\text { alaranjados }\end{array}$ & $\begin{array}{c}\text { *branco que é reflexos } \\
\text { alaranjados } \\
\text { ou } \\
\text { branco com reflexos que são } \\
\text { alaranjados }\end{array}$ \\
\hline branco com reflexos amarelados & $\begin{array}{c}\text { branco que tem reflexos } \\
\text { amarelados }\end{array}$ & $\begin{array}{c}\text { *branco que é reflexos } \\
\text { amarelados } \\
\text { ou } \\
\text { branco com reflexos que são } \\
\text { amarelados }\end{array}$ \\
\hline $\begin{array}{c}\text { branco com reflexos } \\
\text { esverdeados }\end{array}$ & $\begin{array}{c}\text { branco que tem reflexos } \\
\text { esverdeados }\end{array}$ & $\begin{array}{c}\text { *branco que é reflexos } \\
\text { esverdeados } \\
\text { ou } \\
\text { branco com reflexos que são } \\
\text { esverdeados }\end{array}$ \\
\hline rosa-pálido & *rosa que tem pálido & rosa que é pálido \\
\hline vermelho-violáceo & *vermelho que tem violáceo & vermelho que é violáceo \\
\hline
\end{tabular}

\section{Da análise}

Primeiramente, foram propostas conceituações aos termos segundo a teoria dos protótipos. Essa teoria parece ser adequada para descrever o mapeamento conceitual de itens que designam tonalidades, pois "[...] convida [...] a (re)integrar no sentido 
definitório de uma palavra um grande número de propriedades em outro tempo enterradas, por serem consideradas como não diferenciadoras" (KLEIBER, 1990, p. 179, tradução nossa).

À hierarquização proposta pela semântica dos protótipos, serão adicionadas informações que diminuem a distância entre o objeto conceituado e o sujeito que conceitua. Serão consideradas, portanto, as pontuações de Dubois a respeito do léxico visual, que propõem um olhar diferenciado sobre a categorização no léxico visual. As considerações de Dubois revelam características sobre o conceito das tonalidades que só são detectadas quando se propõe a construção de definições, já que a autora não cria um modelo de conceituação, mas levanta aspectos ignorados no estudo do léxico visual. Em seguida, serão propostas definições baseadas nas conceituações propostas.

\section{ANÁLISE DOS DADOS}

\section{A conceituação dos termos}

Nesta seção, a descrição conceitual se pautará nos pressupostos da semântica dos protótipos. Sendo assim, é preciso se perguntar quais são as categorias que constituem o conceito de um termo como vermelho-rubi? Se os conceitos estão estruturados em protótipos, ou seja, por níveis mais prototípicos aos menos prototípicos, como descrever o conceito de um termo como rosado? Para responder a essas perguntas, deve-se verificar em que níveis de categorização os termos se encontram.

A primeira característica a ser notada na análise visual de um vinho é o fato de ele ser branco, rosado ou tinto. Portanto, não parece haver dúvidas de que essas categorias se encontram no nível básico: são categorias que distinguem os vinhos em três grandes grupos e não é possível atribuir uma tonalidade específica a cada uma delas. Após esta análise, já é possível atribuir uma tonalidade mais específica ao vinho. Sendo mais específica, esta tonalidade está em nível subordinado, pois se refere a uma tonalidade muito específica que o vinho pode manifestar. Preenchidos os níveis básico e subordinado, é possível dizer que em um nível anterior ao básico se encontram possibilidades virtuais de constituírem um termo. Entre estas possibilidades, estão as cores básicas e os valores focais.

A partir do que foi exposto acima, a seguinte tabela foi elaborada para os termos que constituem o corpus da presente pesquisa:

Tabela 5 - Níveis de categorização

\begin{tabular}{|c|c|c|c|c|c|c|}
\hline \multicolumn{2}{|c|}{ Níveis } & \multicolumn{5}{|c|}{ Tonalidades } \\
\hline \multirow[b]{2}{*}{ superordenado } & $\begin{array}{c}\text { cores } \\
\text { básicas }\end{array}$ & branco & amarelo & rosa & vermelho & \multirow[b]{2}{*}{$\stackrel{\cup}{\leftrightharpoons}$} \\
\hline & $\begin{array}{l}\text { valores } \\
\text { focais }\end{array}$ & $\begin{array}{l}\text { com reflexos esverdeados } \\
\text { com reflexos amarelados } \\
\text { com reflexos alaranjados } \\
\text { tinto }\end{array}$ & $\begin{array}{l}\text { nítido } \\
\text { dourado } \\
\text { palha } \\
\text { âmbar }\end{array}$ & $\begin{array}{l}\text { pálido } \\
\text { cereja }\end{array}$ & $\begin{array}{l}\text { violáceo } \\
\text { rubi } \\
\text { tijolo }\end{array}$ & \\
\hline \multicolumn{2}{|l|}{ básico } & \multicolumn{2}{|l|}{ branco } & rosado & tinto & $\begin{array}{l}\text { LC/ } \\
\text { LEs }\end{array}$ \\
\hline
\end{tabular}




\begin{tabular}{|c|c|c|c|c|c|c|}
\hline Subordinado & $\begin{array}{l}\text { cores } \\
\text { focais }\end{array}$ & $\begin{array}{l}\text { branco com reflexos } \\
\text { esverdeados } \\
\text { branco com reflexos } \\
\text { amarelados } \\
\text { branco com reflexos } \\
\text { alaranjados } \\
\text { branco de tinto }\end{array}$ & $\begin{array}{l}\text { amarelo } \\
\text { nítido } \\
\text { amarelo- } \\
\text { palha } \\
\text { amarelo } \\
\text { dourado } \\
\text { amarelo- } \\
\text { âmbar }\end{array}$ & $\begin{array}{l}\text { rosa-pálido } \\
\text { rosa-cereja }\end{array}$ & $\begin{array}{l}\text { vermelho- } \\
\text { violáceo } \\
\text { vermelho- } \\
\text { rubi } \\
\text { vermelho- } \\
\text { tijolo }\end{array}$ & 元 \\
\hline
\end{tabular}

Na tabela acima, por exemplo, vermelho aparece como uma cor básica e rubi como um valor focal, ambos no nível superordenado, como possibilidades de constituírem um termo; já no nível subordinado, verifica-se o item já formado. Considerando a dicotomia entre LC e LEs, pode-se dizer que as cores básicas se encontram no âmbito da LC, assim como os valores focais; já as cores focais estão no âmbito das LEs, devido às suas propriedades mais específicas.

A organização das categorias em níveis permite visualizar como essas categorias estão relacionadas entre si. Ao se ter conhecimento de como as categorias estão relacionadas no léxico, há condições de averiguar como as informações estão organizadas no conceito de cada categoria. Ao estipular uma estrutura para os conceitos, é preciso que esta seja suficientemente ampla para poder descrever da melhor forma tanto as informações gerais, como as centrais e as específicas do conceito de cada categoria.

Um dos princípios da semântica dos protótipos é: assim como as categorias estão estruturadas prototipicamente, os conceitos possuem uma estrutura e, pela maneira como as categorias estão organizadas no léxico, esta estrutura também é prototípica. Portanto, o conceito de um termo é formado por planos que vão das informações mais gerais até às informações mais específicas. No primeiro plano, pode-se dizer que esteja a categoria que os indivíduos identificam mais rapidamente, ou seja, as categorias encontradas em nível básico. No primeiro plano do conceito de vermelho-rubi, haverá:

\section{TINTO}

Os segundo e terceiro planos correspondem às categorias encontradas em nível superordenado. Ao se entender que as propriedades conceituais estão organizadas em uma escala de prototipicidade, a cor básica deve aparecer em plano anterior ao do valor focal. No segundo plano, tem-se, então, a cor básica vermelho. E no terceiro plano, temse rubi que, neste caso, é uma metaforização. Se o termo contivesse uma especificação, o valor também apareceria no terceiro plano. É preciso assumir que, em se tratando de planos conceituais, não há uma diferença entre metaforização e especificação.

\section{COR BÁSICA: VERMELHO}

3. VALOR: RUBI

Como foi dito anteriormente, se vermelho-rubi constitui uma cor focal na ASE, então, o termo constitui o conceito das demais categorias que compõem o léxico de tonalidades da ASE. Assim, a informação sobre o lugar desta categoria na escala também é necessária, pois, neste caso, a delimitação da categoria é parte de seu conceito. Esta informação deve aparecer no plano seguinte: 


\section{DELIMITAÇÃO: ENTRE VERMELHO-VIOLÁCEO E VERMELHO-TIJOLO}

Já no quinto plano, estão as informações específicas, menos emblemáticas do conceito, como as indicações sobre o estágio de envelhecimento do vinho, ou, no caso de branco de tinto, sobre o método de elaboração:

\section{INDICATIVO DE VINHO JOVEM}

A estrutura da descrição proposta pode ser considerada adequada, pois é geral (aplica-se a todos os termos que designam cores) e gradual (das características menos específicas às características mais específicas).

Abaixo, na tabela 6, é apresentada a descrição dos conceitos para os termos que compõem o corpus de análise, tendo como início a conceituação das categorias de nível básico, em que nem todos os planos estão preenchidos, já que não possuem todas as informações específicas aos demais termos. Para o segundo plano das categorias básicas, é possível estabelecer que as cores básicas são definidas pela análise dos termos em nível subordinado. Por exemplo, para os vinhos tintos, as categorias em nível subordinado são formadas a partir da cor básica vermelho. Logo, esta deve ser apontada como a cor básica (no segundo plano da descrição) da categoria em nível básico tinto:

Tabela 6 - Conceituação das categorias básicas

\begin{tabular}{|l}
\hline Termo: branco \\
Conceito: 1) BRANCO \\
2) BRANCO \\
3) -- - \\
4) DELIMITAÇÃO: TONALIDADE MAIS CLARA DOS VINHOS \\
5) -- \\
\hline Termo: rosado \\
Conceito: 1) ROSADO \\
2) ROSA \\
3) -- \\
4) DELIMITAÇÃO: TONALIDADE INTERMEDIÁRIA DOS VINHOS, ENTRE O \\
VINHO BRANCO E O VINHO TINTO. \\
5) -- \\
\hline Termo: tinto \\
Conceito: 1) TINTO \\
2) VERMELHO \\
3) -- \\
4) DELIMITAÇÃO: TONALIDADE MAIS ESCURA DOS VINHOS. \\
5) -- \\
\hline
\end{tabular}

Feita a descrição das categorias básicas, o próximo passo é mostrar a organização conceitual das categorias subordinadas, já que, no nível superordenado, não há uma categoria propriamente, mas categorias primárias que constituirão outras ao nível subordinado. Quando se trata de uma tonalidade mais clara ou mais escura de um determinado tipo de vinho, o plano é descrito como a "tonalidade mais clara (ou mais escura) dos vinhos x". A descrição das categorias em nível subordinado é apresentada na tabela 7: 
Tabela 7 - Conceituação das categorias subordinadas

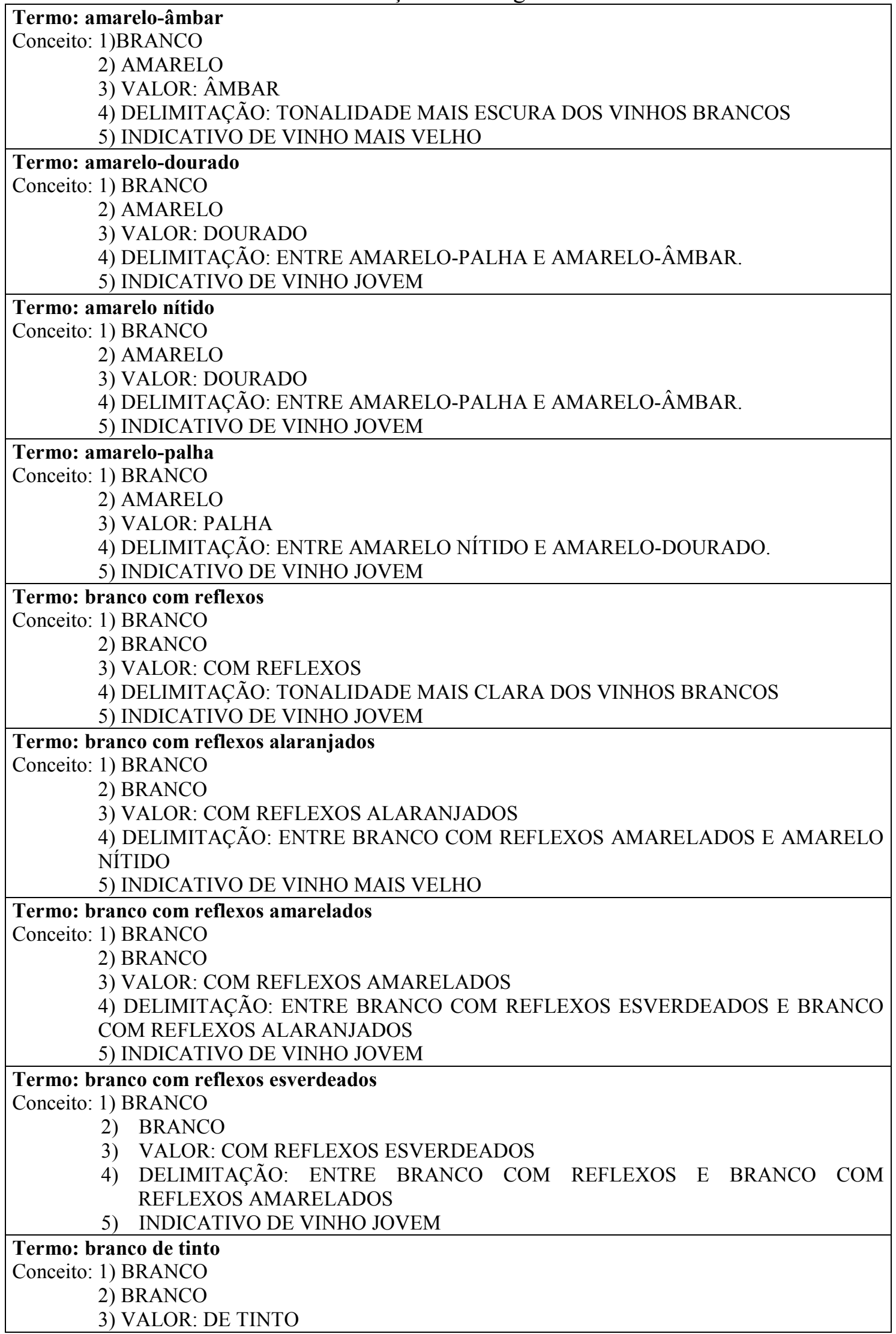




\begin{tabular}{|l|}
\hline 4) -- \\
5) INDICATIVO DO MÉTODO DE ELABORAÇÃO DIFERENCIADO \\
\hline Termo: rosa \\
Conceito: 1) ROSADO \\
2) ROSA \\
3) -- \\
4) DELIMITAÇÃO: TONALIDADE INTERMEDIÁRIA DOS VINHOS ROSADOS, \\
ENTRE O ROSA-CEREJA E O ROSA-PÁLIDO. \\
5) INDICATIVO DE VINHO ROSADO MAIS VELHO \\
\hline Termo: rosa-cereja \\
Conceito: 1) ROSADO \\
2) ROSA \\
3) VALOR: CEREJA \\
4) DELIMITAÇÃO: TONALIDADE MAIS ESCURA DOS VINHOS ROSADOS. \\
5) INDICATIVO DE VINHO ROSADO MAIS VELHO \\
\hline Termo: rosa-pálido \\
Conceito: 1) ROSADO \\
2) ROSA \\
3) VALOR: PÁLIDO \\
4) DELIMITAÇÃO: TONALIDADE MAIS CLARA DOS VINHOS ROSADOS \\
5) INDICATIVO DE VINHO JOVEM \\
Termo: vermelho-rubi \\
Conceito: 1) TINTO \\
2) VERMELHO \\
3) VALOR: RUBI \\
4) DELIMITAÇÃO: ENTRE VERMELHO-VIOLÁCEO E VERMELHO TIJOLO \\
5) INDICATIVO DE VINHO JOVEM \\
\hline Termo: vermelho-tijolo \\
Conceito: 1) TINTO \\
2) VERMELHO \\
3) VALOR: TIJOLO \\
4) DELIMITAÇÃO: TONALIDADE MAIS ESCURA DOS VINHOS TINTOS \\
5) INDICATIVO DE VINHO MAIS VELHO \\
Conceito: 1) TINTO \\
2) VERMELHO \\
3) VALOR: VIOLÁCEO \\
4) DELIMITAÇÃO: TONALIDADE MAIS CLARA DOS VINHOS TINTOS \\
5) INDICATIVO DE VINHO JOVEM \\
\hline
\end{tabular}

Como se pôde observar na tabela 7 , a conceituação dos termos seguiu a estruturação proposta em cinco planos. Com exceção das categorias rosa e branco de tinto, todos os planos estão preenchidos com as informações lexicais correspondentes.

A categoria rosa não apresenta o plano do valor focal, pois se trata de uma unidade terminológica simples. Já a categoria branco de tinto não apresenta indicações sobre a sua delimitação, pois não se trata exatamente de uma tonalidade, mas de um tipo de vinho cujo método de elaboração é diferenciado. Ainda assim, não se trata de uma categoria em nível básico, pois veicula informações bem mais específicas do que as categorias branco, rosado e tinto. A delimitação da categoria não se constitui em uma informação desnecessária, pois foi entendida como uma propriedade conceitual dos termos que designam tonalidades, uma vez que se constituem como cores focais no âmbito da ASE. 
A descrição conceitual em cinco planos prevista pela semântica dos protótipos já permite elaborar algumas definições aos termos. Por exemplo, a partir da descrição proposta anteriormente, a seguinte definição para o termo vermelho-rubi parece adequada:

ENTRADA: vermelho-rubi

DEFINIÇÃO: Tonalidade (2) avermelhada dos (1) vinhos tintos que se assemelha à cor do (3) rubi e que se estabelece entre (4) as tonalidades vermelho-violáceo e vermelhotijolo. (5) A tonalidade é indicativa de vinho jovem.

Nessa definição, cada número corresponde a um plano da descrição conceitual. Por exemplo, o quinto plano, o das informações mais específicas, aparece seguido da frase: "A tonalidade é indicativa de vinho jovem". Porém, nem todos os itens parecem se adequar a esse tipo de definição, o que indica que há mais propriedades que devem ser descritas e que estão ligadas à maneira como as categorias são percebidas.

Ainda considerando a descrição proposta pela semântica dos protótipos, certas definições contêm algumas informações que podem ser suprimidas, para não haver redundância. É o que se constata nas definições das categorias em nível básico:

ENTRADA: branco

DEFINIÇÃO: (?) tonalidade branca dos vinhos brancos. Tonalidade mais clara dos vinhos.

ENTRADA: rosado

DEFINIÇÃO: (?) tonalidade rosa dos vinhos rosados. Tonalidade intermediária entre a tonalidade do vinho branco e do vinho tinto.

ENTRADA: tinto

DEFINIÇÃO: (?) tonalidade vermelha dos vinhos tintos. Tonalidade mais escura dos vinhos.

Não é necessário dizer que os vinhos brancos apresentam tonalidade branca, mesmo que algumas tonalidades atribuídas a esse tipo de vinho contenham a cor básica amarelo. Portanto, a descrição desses termos está incompleta, já que apresentam outras características que não aparecem diretamente nos cinco planos da descrição conceitual. Mas que características são essas? As categorias branco, rosado ou tinto não se referem somente a tonalidades centrais do vinho, mas ao tipo de uva que permitiu a fabricação do vinho naquela tonalidade. Esta informação pode ser adicionada ao primeiro plano da descrição conceitual. Repete-se aqui a descrição de branco com o acréscimo dessa informação, como se observa na tabela 8:

Tabela 8 - Conceituação das categorias básicas - revisão

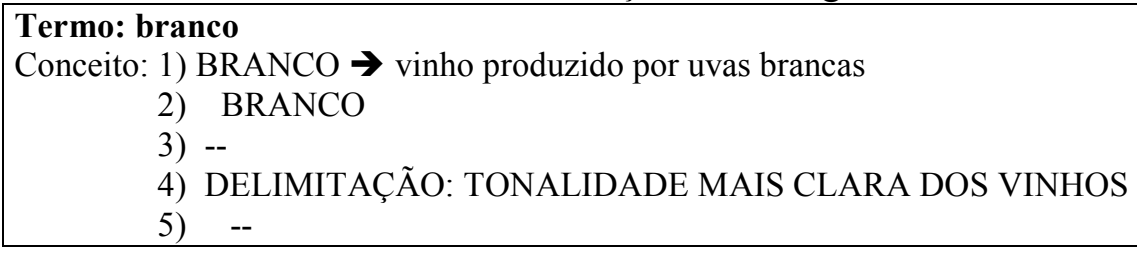


Como se constata na tabela 8 , trata-se de uma informação adicional ao conceito, pois está vinculada a um certo tipo de conhecimento sobre os vinhos. Nota-se que a adição da informação melhora consideravelmente a elaboração da definição de branco:

ENTRADA: branco

DEFINIÇÃO: Tonalidade de um tipo de vinho produzido com uvas brancas (1). Estabelecida como a tonalidade mais clara dos vinhos (4).

Por que as propriedades que apareceram para se evitar uma redundância só foram constatadas quando se principiou a proposição de uma definição aos termos? É nesse ponto que as considerações de Dubois sobre os princípios organizacionais da categorização mostram-se fundamentais. A informação de que o vinho branco é produzido a partir de certo tipo de uva não é um tipo de informação constatada diretamente. A informação parece ser instaurada como uma causa para que o vinho manifeste aquela determinada tonalidade.

Apontar esta causa significa apontar que a propriedade produzido com uvas brancas está relacionada a determinado tipo de conhecimento distinto do conhecimento que permite reconhecer uma tonalidade. Entretanto, parece existir um tipo de interação entre o conhecimento que permite reconhecer uma tonalidade (como o ato de reconhecer que o vinho é branco) e o conhecimento que o sujeito possui sobre aquela tonalidade (o ato de reconhecer que a tonalidade é indicativa que o vinho foi produzido a partir de certa espécie de uva). A relação entre os dois tipos de conhecimento pode ser esquematizada da seguinte maneira:
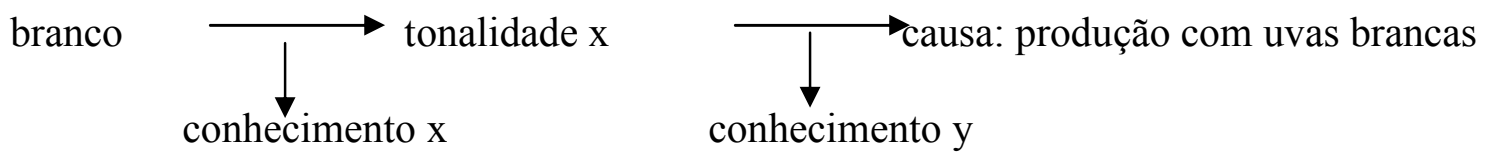

Abrangendo os dois tipos de conhecimento, está a percepção, não como: "um processo bottom-up, mas uma habilidade complexa dirigida por práticas culturais" (DUBOIS, 1997, p. 188, grifos da autora). Além disso, para que se estabeleça a ligação entre tonalidade $x$ e produção com uvas brancas, deve haver a intervenção de um sujeito, cujo conhecimento permite relacionar as duas propriedades. Provavelmente, por ser dependente do conhecimento do sujeito, e não algo que pode ser constatado a partir das descrições físicas da tonalidade, a informação "produzido por uvas brancas" só se tornou evidente quando se propôs uma definição àquelas tonalidades.

A partir desta conclusão, o quinto plano da descrição conceitual, sobre o estágio de envelhecimento do vinho, é também uma informação que apenas um especialista em Enologia poderia apontar. Sob a perspectiva da semântica dos protótipos, esta informação é tratada como uma propriedade conceitual menos prototípica, dado o seu caráter mais específico. $\mathrm{Na}$ perspectiva de Dubois, trata-se de uma informação dependente da percepção de um sujeito: uma propriedade que não está situada perifericamente, mas na relação entre o objeto conceituado e o sujeito que conceitua.

Baseando-se na conceituação da semântica dos protótipos, pode-se atribuir a seguinte definição ao termo amarelo nítido: 
ENTRADA: amarelo-nítido

DEFINIÇÃO: (?) Tonalidade (2) amarelada dos (1) vinhos brancos que é nítida (3) e que se estabelece (4) entre a tonalidade branco com reflexos alaranjados e a tonalidade amarelo-palha. (5) A tonalidade é indicativa de vinho jovem.

A definição acima seguiu o mesmo padrão das anteriores, com a diferença que para a expressão do valor focal utilizou-se outro tipo de construção sintática análoga. Todavia, a expressão do valor focal está confusa: como se pode explicar que a nitidez é uma característica de uma tonalidade?

Esta questão parece refletir o fato de que a objetividade da percepção visual é apenas parcial. Se fosse total, como geralmente se supõe, os valores focais ligados a nitidez ou palidez seriam expressados pela propriedade a que se referem. Como não é o caso, é preciso considerar nitidez como uma propriedade percebida por um determinado sujeito, atribuída com base em um processo subjetivo. Considerando esta perspectiva, a definição pode ser refeita indicando-se que a tonalidade é característica pela sua propriedade de ser $x$ em comparação às demais tonalidades:

ENTRADA: amarelo-nítido

DEFINIÇÃO: Tonalidade (2) amarelada dos (1) vinhos brancos que é característica pela sua propriedade de ser nítida em comparação às demais tonalidades (3). A tonalidade se estabelece (4) entre a tonalidade branco com reflexos alaranjados e a tonalidade amarelo-palha. (5) A tonalidade é indicativa de vinho jovem.

A partir do que foi exposto, são propostas as seguintes definições para todos os termos que compõem o corpus.

Tabela 9 - Definições

\begin{tabular}{|c|}
\hline $\begin{array}{l}\text { Entrada: branco } \\
\text { Definição: Tonalidade de um tipo de vinho produzido com uvas brancas (1). Estabelecida como a } \\
\text { tonalidade mais clara dos vinhos (4). }\end{array}$ \\
\hline $\begin{array}{l}\text { Entrada: rosado } \\
\text { Definição: Tonalidade de um tipo de vinho produzido pela fermentação do mosto de uvas tintas (1). } \\
\text { Estabelecida como a tonalidade intermediária entre a tonalidade do vinho branco e do vinho tinto (4). }\end{array}$ \\
\hline $\begin{array}{l}\text { Entrada: tinto } \\
\text { Definição: Tonalidade de um tipo de vinho produzido com uvas tintas (1). Estabelecida como a } \\
\text { tonalidade mais escura dos vinhos (4). }\end{array}$ \\
\hline $\begin{array}{l}\text { Entrada: amarelo-âmbar } \\
\text { Definição: Tonalidade (2) amarelada dos (1) vinhos brancos que se assemelha à cor do (3) âmbar e que } \\
\text { se estabelece (4) como uma das tonalidades mais escuras dos vinhos brancos. (5) A tonalidade é } \\
\text { indicativa de um vinho mais velho. }\end{array}$ \\
\hline $\begin{array}{l}\text { Entrada: amarelo-dourado } \\
\text { Definição: Tonalidade (2) amarelada dos (1) vinhos brancos que se assemelha à cor (3) dourada e q } \\
\text { estabelece (4) entre as tonalidades amarelo-palha e amarelo-âmbar. (5) A tonalidade é indicativa d }\end{array}$ \\
\hline
\end{tabular}




\begin{abstract}
Entrada: amarelo nítido
Definição: Tonalidade (2) amarelada dos (1) vinhos brancos que é característica pela sua propriedade de ser nítida em comparação às demais tonalidades (3). A tonalidade se estabelece (4) entre a tonalidade branco com reflexos alaranjados e a tonalidade amarelo-palha. (5) A tonalidade é indicativa de vinho jovem.
\end{abstract}

\title{
Entrada: amarelo-palha
}

Definição: Tonalidade (2) amarelada dos (1) vinhos brancos que se assemelha à cor da (3) palha e que se estabelece (4) entre as tonalidades amarelo nítido e amarelo-dourado. (5) A tonalidade é indicativa de vinho jovem.

\section{Entrada: branco com reflexos}

Definição: Tonalidade dos (1 e 2) vinhos brancos que têm reflexos (3). A tonalidade se estabelece (4) como a tonalidade mais clara dos vinhos, cujos reflexos podem ter cores variadas. (5) A tonalidade é indicativa de vinho jovem.

\section{Entrada: branco com reflexos alaranjados}

Definição: Tonalidade dos (1 e 2) vinhos brancos que têm reflexos alaranjados (3). A tonalidade se estabelece (4) entre a tonalidade branco com reflexos amarelados e amarelo nítido. (5) A tonalidade é indicativa de vinho mais velho.

\section{Entrada: branco com reflexos amarelados}

Definição: Tonalidade dos (1 e 2) vinhos brancos que têm reflexos amarelados (3). A tonalidade se estabelece (4) entre a tonalidade branco com reflexos esverdeados e branco com reflexos alaranjados. (5) A tonalidade é indicativa de vinho jovem.

\section{Entrada: branco com reflexos esverdeados}

Definição: Tonalidade dos (1 e 2) vinhos brancos que têm reflexos esverdeados (3). A tonalidade se estabelece (4) como a tonalidade mais clara dos vinhos, entre a tonalidade branco com reflexos e branco com reflexos amarelados. (5) A tonalidade é indicativa de vinho jovem.

\section{Entrada: branco de tinto}

Definição: Tonalidade branca dos (1 e 2) vinhos tintos. (5) A tonalidade é indicativa de que o vinho é produzido a partir de uvas tintas vinificadas de bica aberta.

\section{Entrada: rosa}

Definição: Tonalidade (1) dos vinhos rosados que se estabelece (4) como tonalidade intermediária dos vinhos rosados, entre o rosa-cereja e o rosa-pálido. (5) A tonalidade é indicativa de vinho mais velho.

\section{Entrada: rosa-cereja}

Definição: Tonalidade (1) dos vinhos rosados que se assemelha à cor da cereja (3) e que se estabelece (4) como tonalidade mais escura dos vinhos rosados. (5) A tonalidade é indicativa de vinho mais velho.

\section{Entrada: rosa-pálido}

Definição: Tonalidade dos (1) vinhos rosados que é característica pela sua propriedade de ser pálida em relação às demais tonalidades (3). A tonalidade se estabelece (4) como a tonalidade mais clara dos vinhos rosados. (5) A tonalidade é indicativa de vinho jovem.

\section{Entrada: vermelho-rubi}

Definição: Tonalidade (2) avermelhada dos (1) vinhos tintos que se assemelha à cor do (3) rubi e que se estabelece entre (4) as tonalidades vermelho-violáceo e vermelho-tijolo. (5) A tonalidade é indicativa de vinho jovem.

\section{Entrada: vermelho-tijolo}

Definição: Tonalidade (2) avermelhada dos (1) vinhos tintos que se assemelha à cor do (3) tijolo e que se estabelece como (4) a tonalidade mais escura dos vinhos tintos. (5) A tonalidade é indicativa de vinho mais velho. 
Como podemos observar nas definições propostas acima, construções redundantes como tonalidade branca dos vinhos brancos ou tonalidade rosada dos vinhos rosados foram evitadas. Esse tipo de construção permitiu apenas a ocorrência de tonalidade avermelhada dos vinhos tintos. Os casos de metaforização foram elaborados a partir da construção sintática [que se assemelha a]. Já os casos de especificação, exigiram a construção [que é característica pela sua propriedade de ser x em relação às demais tonalidades].

Os resultados acima indicam que a descrição das propriedades conceituais, por um lado, não é suficiente para se estabelecer um padrão definitório geral e aplicável a todos os casos. Como foi constatado, a semântica dos protótipos possibilitou a descrição conceitual baseada em cinco planos e permitiu a formulação de definições para alguns termos, mas não para todos. As categorias básicas, como branco, rosado ou tinto, por conterem propriedades mais prototípicas, resultaram em definições incompletas ou redundantes, pois faltavam especificar informações que dependiam do conhecimento do sujeito sobre as categorias. Por este motivo, a descrição é necessária na medida em que permite verificar que tipo de informações é necessário constar em uma definição de uma tonalidade.

\section{REFERÊNCIAS}

ABE - ASSOCIAÇÃO BRASILEIRA DE ENOLOGIA. Disponível em: http://www.enologia.org.br/include.asp?sSecao=fotos\&sParam=includes/galeria pt.asp, Acesso em 29 nov. 2006

ABREU, Sabrina P. de \& LARA, Leandro Z. O tratamento semântico do léxico enológico: o caso das impressões sensoriais. In: FAULSTICH, E. \& ABREU, S. P. (orgs.) Lingüística aplicada à terminologia e à lexicologia: cooperação internacional: Brasil e Canadá. Porto Alegre: UFRGS, Instituto de letras, NEC. P. 33 - 58, 2003.

ACADEMIA DO VINHO. Disponível em <http://www.academiadovinho.com.br>. Acesso em 17 nov. 2006.

CANÇADO, Márcia. Manual de semântica: noções básicas e exercícios. Belo Horizonte, Editora UFMG, 2005, 185p.

DUBOIS, Danièle. Cultural beliefs as non-trivial constraints on categorization: evidence from colors and odors. Behavioral and Brain Science. 20, 2. 1997.

DUBOIS, Danièle. Categories as acts of meaning: the case of categories in olfaction and audition. Cognitive Science Quaterly. 2000, 1, 35-68. 2000.

DUBOIS, Danièle. Conceptualisations de la couleur: pratiques et denominations. In: íris, essence et sens dês couleurs. Nancy, França, 2005. Disponível em: $<$ www.ensaia.inpl-nancy-fr/iris/pdf/D_Dubois.pdf $>$. Acesso em 01 nov. 2006.

E-MERCATURA.NET - Divulgação dos vinhos do Norte - Disponível em $<\underline{\mathrm{http}}$ ://www.e-mercatura.net/html/pt/glossario.asp?letra=B $>$. Acesso em 15 nov. 2006. 
KLEIBER, Georges. La semántica de los prototipos: categoría y sentido léxico. Tradução: António Rodriguez. Madri: Visor Libros, 1990.

KRIEGER, Maria da Graça e FINATTO, Maria José Bocorny. Introdução à terminologia: teoria e prática. São Paulo: Contexto, 2004.

LARA, Leandro Z. As categorias semântico-lexicais no âmbito das linguagens de especialidade. $\quad$ UERJ: $2002 . \quad$ Disponível em $<$ http://www.filologia.org.br/vicnlf/anais/caderno07-06.html $>$. Acesso em 07 abr. 2006. MANFROI, Vitor. Degustação de vinhos. Porto Alegre: Editora da UFRGS, 2004. OLIVEIRA, Roberta Pires de. Semântica. In: MUSSALIM, F. ; BENTES, A. C. (org.) Introdução à Lingüística: domínios e fronteiras. São Paulo: Cortez. Vol.2, 2001.

PEARSON, Jennifer. Comment accéder aux éléments définitoires dans les textes spécialisés?. Terminologies Nouvelles $\mathrm{n}^{\circ} 19$, mai 1999. Tradução: Carolina Huang e Sandra Dias Loguercio. Revisão: Luzia Araújo.

POITOU, Jacques, \& DUBOIS, Danièle. Catégories sémantiques et cognitives :Une étude expérimentale en sémantique lexicale. Cahiers de lexicologie, 74, 15-27. 1999.

REY, Alain. La terminologie: noms et notions. 2e. éd. corr. Paris: Puf, 1992, c1979. $127 \mathrm{p}$

SILVA, Augusto Soares da. A Semântica de deixar: uma contribuição para a abordagem cognitiva em Semântica Lexical. Lisboa: FCG, 1999. 727 p.

SIQUEIRA, Elizandra de. O Constructo de Faulstich (2003): um estudo dos formativos no léxico da análise sensorial enológica. 2004. V.2. Dissertação (Mestrado em Teoria e Análise Lingüística).

WILSON, John. Pensar com conceitos. Tradução Waldéia Barcellos. São Paulo: Martins fontes, 2001. 